\title{
HUBUNGAN ANTARA NYERI REUMATOID ARTRITIS DENGAN KEMANDIRIAN ADL PADA LANSIA
}

\author{
Kartini $^{1}$, E. Samaran ${ }^{1}$, Serly A. Marcus ${ }^{1}$ \\ ${ }^{1}$ Jurusan Keperawatan Politeknik Kesehatan Sorong \\ email :kunsamaran99@gmail.com
}

\begin{abstract}
ABSTRACK
Arthritis or commonly called rheumatism is a disease that attacks the joints and surrounding structures. Rheumatic disease in the community is often considered a trivial disease because it does not cause death, but if not treated quickly rheumatism can make limbs function abnormally, starting from bumps, stiff joints, difficulty walking, even lifelong disability. Objective: to find out there is a relationship between rheumatoid arthritis pain and independence of Activity daily living $(A D L)$ in the elderly. Research Methods: This study used a quantitative research design with a cross sectional approach to reveal the relationship between independent variables (Rheumatoid Arthritis pain) and the dependent variable of Independent Activity daily living (ADL) at the same time and once a measurement. Statistical tests using chi-square consisted of 33 respondents. Results: From the results of the chi-square statistical test obtained $p$ value $=0.047(p<0.05)$ there was a relationship between rheumatoid arthritis pain and the independence of the elderly in the puskesmas classaman city of Sorong. Conclusion: There is a relationship between Rheumatoid Arthritis pain and the degree of independence in carrying out daily life activities in the elderly in the working area of the Sorong City Community Health Center ( $p$ value $==, 047$ )

Keywords: Rheumatoid Pain Arthritis; Elderly ADL

Bibliography: $2002-2017$
\end{abstract}

\begin{abstract}
ABSTRAK
Arthritis atau biasa disebut rematik adalah penyakit yang menyerang persendian dan struktur di sekitarnya. Penyakit rematik pada masyarakat sering dianggap penyakit sepele karena tidak menimbulkan kematian, tetapi bila tidak ditangani secara cepat rematik bisa membuat anggota tubuh berfungsi tidak normal, mulai dari benjol-benjol, sendi kaku, sulit berjalan, bahkan kecacatan seumur hidup. Tujuan : untuk mengetahui ada hubungan antara nyeri rematoid artritis dengan kemandirian Activity daily living (ADL) pada lansia. Metode Penelitian : Penelitian ini menggunakan desain penelitian kuantitatif dengan pendekatan cross sectional untuk mengungkapkan hubungan antara variabel independen (nyeri Reumatoid Arthritis) dan variabel dependen Kemandirian Activity daily living(ADL) dalam waktu yang bersamaan serta sekali pengukuran. Uji statistik menggunakan chisquare terdiri dari 33 responden. Hasil : Dari hasil uji statistik chi-square di peroleh nilai $p=0,047$ $(\mathrm{p}<0,05)$ ada hubungan antara nyeri reumatoid artritis dengan kemandirian lansia di puskesmas klasaman kota sorong. Kesimpulan : Ada hubungan antara nyeri Reumatoid Artritis dengan tingkat kemandirian dalam melakukan aktivitas kehidupan sehari-hari pada lanjut usia di wilayah kerja Puskesmas Klasaman Kota Sorong ( $\mathrm{p}$ value sebesar $=, 047$ )
\end{abstract}

Kata Kunci

: Nyeri Reumatoid Artritis ; ADL Lansia

Daftar Pustaka

: 2002-2017 


\section{PENDAHULUAN}

Arthritis atau biasa disebut rematik adalah penyakit yang menyerang persendian dan struktur di sekitarnya. Penyakit rematik pada masyarakat sering dianggap penyakit sepele karena tidak menimbulkan kematian, tetapi bila tidak ditangani secara cepat rematik bisa membuat anggota tubuh berfungsi tidak normal, mulai dari benjol-benjol, sendi kaku, sulit berjalan, bahkan kecacatan seumur hidup. Rasa sakit yang timbul bisa sangat mengganggu dan membatasi aktivitas kegiatan sehari-hari (Nainggolan, 2009).

Bagian sinovial sendi, sarung tendon dan bursa akan mengalami penebalan akibat radang yang diikuti oleh erosi tulang dan destruksi tulang disekitar sendi (Chabib, Ikawati, Martien, \& Ismail, 2016). Dampak dari pasien rematoid arthritis dapat menimbulkan rasa ketidaknyamanan, yang disebabkan oleh dampak dari keterbatasan mobilisasi fisik ini juga dapat menimbulkan kecacatan seperti kelumpuhan dan gangguan aktivitas hidup sehari-hari tetapi juga efek sistemik yang tidak jelas tetapi dapat menimbulkan kegagalan organ dan kematian atau mengakibatkan masalah seperti rasa nyeri, keadaan mudah lelah, perubahan citra diri serta resiko tinggi terjadi cidera (Kisworo, 2008) di kutip oleh (Nadliroh, 2014).

Menurut Arthritis Foundation (2015) dalam (Chabib, Ikawati, Martien, \& Ismail, 2016), sekitar 3\% atau 1,5 juta orang dewasa mengalami RA (Arthritis Foundation, 2015). RA terjadi pada 0,5-1\% populasi orang dewasa di negara maju. Di Indonesia jumlah penderita reumatoid arthritis padatahun 2013 berjumlah 27,7\% dan prevalensi reumatoid arthritis untuk wilayah Papua Barat berjumlah $15,5 \%$ menurut riset kesehatan dasar. (Badan Penelitian dan Pengembangan Kesehatan, 2013).

Hasil penelitian yang pernah dilakukan menunjukkan ada hubungan nyeri rhemathoid arthritis dengan kemandirian dalam aktivitas kehidupan sehari-hari pada lansia di Posbindu Karang Mekar terdapat hubungan yang signifikan antara nyeri rhematoid arhtritis dengan kemandirian pada lansia (Chintyawati, 2014). Berdasarkan studi pendahuluan yang dilakukan oleh peneliti di Puskesmas Klasaman pada tanggal 16 April 2018, didapat angka kejadian reumatoid arthritis pada tahun 2016 berjumlah 1402 jiwa, pada tahun 2017 terjadi penurunan yang signifikan yaitu 236 jiwa serta pada tahun 2018 pada tanggal 01 Januari s/d 16 April berjumlah 67 jiwa.

\section{METODE}

Penelitian ini menggunakan desain penelitian kuantitatif dengan pendekatan cross sectional untuk mengungkapkan hubungan antara variabel independen (nyeri Reumatoid Arthritis) dan variabel dependen Kemandirian Activity daily living (ADL) dalam waktu yang bersamaan serta sekali pengukuran.

Populasi dalam penelitian ini adalah seluruh klien lansia diwilayah kerja puskesmas Klasaman yang menderita arthritis reumatoid pada tahun 2017. Berdasarkan pengambilan data pada tanggal 01 
Januari s/d 16 April 2018 berjumlah 67 jiwa. Pada saat pengambilan data awal, populasi yang didapatkan sebanyak 67 sehingga menggunakan rumus purposive sampling hasil yang didapatkan 40 sampel kemudian saat penelitian dilapangan hasil yang didapatkan 33 respon.

\section{HASIL DAN PEMBAHASAN}

1. Karakteristik Responden

a. Usia

Distribusi frekuensi responden berdasarkan usia dalam penelitian ini dapat ditunjukkan pada tabel 4.1 sebagai berikut ;

Tabel 4.1 Distribusi

Frekuensi Responden

Berdasarkan Usia Di

Puskesmas Klasaman Kota Sorong

\begin{tabular}{lccc}
\hline No & Kategori & Frekuensi & $\%$ \\
\hline 1 & $60-74$ & 29 & 88 \\
\hline 2 & $75-90$ & 4 & 12 \\
\hline & Total & 33 & 100 \\
\hline
\end{tabular}

Berdasarkan tabel 4.1 ditunjukkan bentuk frekuensi responden berdasarkan usia. Kategori usia 60-74 tahun memperoleh jumlah tertinggi yaitu sebesar 33 responden (88\%).

b. Jenis Kelamin

Distribusi frekuensi

responden berdasarkan jenis kelamin dalam penelitian ini dapat ditunjukkan pada tabel 4.2 sebagai berikut ;

Tabel 4.2 Distribusi Frekuensi Responden Berdasarkan Jenis
Kelamin Di Puskesmas Klasaman Kota Sorong

\begin{tabular}{lccc}
\hline No & Kategori & Frekuensi & $\%$ \\
\hline 1 & Laki-laki & 14 & 42 \\
\hline 2 & Perempuan & 19 & 58 \\
\hline & Total & 33 & 100 \\
\hline
\end{tabular}

Berdasarkan tabel 4.2 ditunjukkan distribusi frekuensi berdasarkan jenis kelamin perempuan diperoleh jumlah tertinggi yaitu sebesar 19 responden (58\%) dibandingkan jenis kelamin laki-laki dengan jumlah 14 responden $(42 \%)$.

2. Analisa Univariat

a. Distribusi frekuensi nyeri Rheumatoid Arthritis berdasarkan lanjut usia.

Distribusi frekuensi responden berdasarkan frekuensi nyeri pada lanjut usia dalam penelitian ini dapat ditunjukkan pada tabel 4.3 sebagai berikut ;

Tabel 4.3 Distribusi

Frekuensi Nyeri Rheumatoid Arthritis Berdasarkan Lanjut Usia Di Puskesmas Klasaman Kota Sorong

\begin{tabular}{cccc}
\hline No & $\begin{array}{c}\text { Nyeri } \\
\text { Rheumatoid } \\
\text { Arthritis }\end{array}$ & Frekuensi & $\%$ \\
\hline 1 & Nyeri rendah & 28 & 85 \\
\hline 2 & Nyeri tinggi & 5 & 15 \\
\hline & Total & 33 & 100 \\
\hline
\end{tabular}

Berdasarkan tabel 4.3 ditunjukkan bahwa dari 33 responden sebagian besar responden memiliki nyeri rheumatoid artritis rendah yaitu 28 responden $(85 \%)$ dan yang paling 
kecil adalah nyeri rheumatoid artritis tinggi yaitu 5 responden (15\%) .

b. Distribusi tingkat kemandirian lanjut usia

\begin{tabular}{lr}
\multicolumn{2}{c}{ Distribusi frekuensi } \\
responden berdasarkan tingkat \\
kemandirian lanjut usia dalam \\
penelitian ini dapat ditunjukkan pada \\
tabel 4.4 sebagai berikut ;
\end{tabular}

Tabel 4.4 Distribusi frekuensi tingkat kemandirian lanjut usia di Puskesmas Klasaman

\begin{tabular}{cccc}
\hline No & $\begin{array}{c}\text { Tingkat } \\
\text { kemandirian }\end{array}$ & Frekuensi & $\%$ \\
\hline 1 & Tergantung & 12 & 36 \\
\hline 2 & Mandiri & 21 & 64 \\
\hline & Total & 33 & 100 \\
\hline
\end{tabular}

Berdasarkan tabel 4.4 ditunjukkan bahwa distribusi tingkat kemandirian yang paling besar yaitu tingkat kemandirian mandiri sebanyak 21 responden $(64 \%)$ sedangkan tingkat kemandirian terkecil yaitu tingkat kemandirian tergantung sebanyak 12 responden $(36 \%)$.

3. Analisa Bivariat

a. Hubungan antara nyeri Rheumatoid Arthritis dengan tingkat kemandirian pada lansia

Tabel 4.5 Hubungan antara nyeri Rheumatoid Arthritis dengan tingkat kemandirian lansia

\begin{tabular}{cccccc}
\hline Variabel & \multicolumn{3}{c}{ Tingkat kemandirian } & & \multirow{2}{P}{$\begin{array}{c}\mathrm{P} \\
\text { value }\end{array}$} \\
\cline { 2 - 4 } & \multicolumn{2}{c}{ Tergantung } & Mandiri & & \\
\cline { 1 - 4 } $\begin{array}{c}\text { Nyeri } \\
\text { RA }\end{array}$ & $\mathrm{F}$ & $\%$ & $\mathrm{~F}$ & $\%$ & \\
\cline { 1 - 4 } Ringan & 8 & 67 & 20 & 95 & \multirow{2}{*}{0,047} \\
\hline Sedang & 4 & 33 & 1 & 5 & \\
\hline Total & 1 & 10 & 21 & 10 & \\
& 2 & 0 & & 0 & \\
\hline
\end{tabular}

Berdasarkan pada tabel 4.5 ditunjukkan mayoritas responden mandiri dan memiliki nyeri rendah, yaitu sebesar 20 responden (95\%). Analisa hubungan antara nyeri Rheumatoid Arthritis dengan tingkat kemandirian dalam melakukan aktivitas sehari-hari pada lansia di wilayah kerja Puskesmas Klasaman Kota Sorong ini menggambarkan uji Chi Squared. Hasil penelitian diperoleh nilai $\mathrm{p}$ value 0,047 ( $\mathrm{p}<$ $0,05)$ yang berarti pada alpha $5 \%$, terlihat ada hubungan yang yang bermakna antara nyeri Reumatoid Arthritis dengan tingkat kemandirian dalam melakukan aktivitas seharihari pada lansia di wilayah kerja puskesmas Klasaman Kota Sorong.

\section{PEMBAHASAN}

Hubungan nyeri reumatoid artritis dengan tingkat kemandirian lansia di puskesmas klasaman kota sorong

Dari hasil uji statistik chisquare di peroleh nilai $\mathrm{p}=0,047(\mathrm{p}$ $<0,05)$ ada hubungan antara nyeri reumatoid artritis dengan kemandirian lansia di puskesmas klasaman kota sorong. Hal yang signifikan tersebut juga bisa dilihat dari fakta di lapangan yang dapat dilihat dari hasil data yang diperoleh dari hasil koesioner pada saat penelitian.

Hasil penelitian ini sejalan dengan penelitian yang pernah dilakukan dimana ada hubungan 
yang signifikan antara nyeri reumatoid artritis dengan kemandirian pada lansia Di Wilayah Kerja Puskesmas Pisangan Tangerang Selatan (Chintyawati, 2014).

Nyeri sendi pada reumatoid artritis membuat penderitanya seringkali takut untuk bergerak sehingga mengganggu aktivitas sehari-harinya dan dapat menurunkan produktivitasnya. Penurunan kemampuan muskuloskeletal karena nyeri sendi dapat juga menurunkan aktivitas fisik dan latihan, sehingga akan mempengaruhi lansia dalam melakukan aktivitas kehidupan sehari-hari activity of daily living (ADL). Aktivitas sehari-hari yang dimaksud seperti makan, minum, berjalan, tidur, mandi, berpakaian, dan buang air besar atau kecil.

Dari kemampuan melakukan aktivitas tersebut dapat dinilai apakah lanjut usia mandiri atau tergantung pada orang lain. Mandiri dalam melakukan aktivitas kehidupan sehari-hari adalah kebebasan untuk bertindak, tidak tegantung pada pihak lain dalam merawat diri maupun dalam beraktivitas sehari-hari. Semakin mandiri status fungsional lansia maka kemampuan untuk bertahan terhadap serangan penyakit akan semakin baik. Sebaliknya lansia yang menunjukkan ketergantungan akan rentan terhadap serangan penyakit.

\section{KESIMPULAN}

1. Karakteristik lansia di wilayah kerja Puskesmas Klasaman Kota Sorong mayoritas dalam rentang umur 60-74 tahun dan jenis kelamin sebagian besar perempuan.

2. Lansia di wilayah kerja Puskesmas Klasaman Kota Sorong sebagian besar memiliki tingkat kemandirian tinggi dalam aktivitas kehidupan sehari-hari yaitu sebesar 21 responden (64\%).

3. Lansia di wilayah kerja Puskesmas Klasaman Kota Sorong memiki tingkat nyeri Reumatoid Artritis rendah yaitu sebesar 28 responden $(85 \%)$

4. Ada hubungan yang bermakna antara nyeri Reumatoid Artritis dengan tingkat kemandirian dalam melakukan aktivitas kehidupan sehari-hari pada lanjut usia di wilayah kerja Puskesmas Klasaman Kota Sorong ( $\mathrm{p}$ value sebesar = ,047)

\section{SARAN}

1. Bagi Institusi Pendidikan

Hasil penelitian ini dapat dijadikan sebagai rujukan tambahan bagiinstitusi pendidikan. Misalnya hasil penelitian ini dapat digunakan sebagai referensi yang dapat menambah pengetahuan mahasiswa terhadap nyeri Reumatoid Artritis yang berhubungan dengan tingkat kemandirian dalam aktivitas kehidupan sehari-hari pada lansia. 
2. Bagi Puskesmas Klasaman Kota Sorong

a. Diharapkan tenaga kesehatan yang mengelola program posbindu memberikan dukungan kepada keluarga lanjut usia agar senantiasa mengikuti program posbindu sehingga lanjut usia yang berada di wilayah kerja Puskesmas Klasaman Kota Sorong mengetahui kondisi kesehatannya setiap bulan.

b. Terkait hasil dalam penelitian ini lanjut usia yang berada di wilayah kerja Puskesmas Klasaman Kota Sorong yang memiliki tingkat ketergantungan dan memiliki nyeri Reumatoid Artritis tinggi yang terbanyak adalah jenis kelamin perempuan. Diharapkan adanya penyuluhan kesehatan yang berkaitan dengan lanjut usia seperti nyeri Reumatoid Artritis yang mengganggu aktivitas sehari-hari lanjut usia khususnya untuk lanjut usia yang berjenis kelamin perempuan. Serta diharapkan kepada petugas kesehatan untuk melakukan penyuluhan kepada lansia untuk mengatasi nyeri Reumatoid Artritis secara alami dengan teknik kompres air hangat terhadap bagian yang nyeri.

c. Bagi Peneliti Selanjutnya Untuk pengambilan data sebaiknya tidak diikuti dengan kegiatan posbindu lainnya, karena penelititerburu-buru dalam mewawancarai responden dan bisa menimbulkan bias informasi.

\section{DAFTAR PUSTAKA}

Badan Penelitian dan Pengembangan Kesehatan. (2013). Riset Kesehatan Dasar (RISKESDAS) 2013. Laporan Nasional 2013, 1-384. https://doi.org/1 Desember 2013

Chabib, L., Ikawati, Z., Martien, R., \& Ismail, H. (2016a). Review Rheumatoid Arthritis: Terapi Farmakologi , Potensi Kurkumin dan Analognya , serta Pengembangan Sistem Nanopartikel. Jurnal Pharmascience, 3(1), 10-18.

Chabib, L., Ikawati, Z., Martien, R., \& Ismail, H. (2016b). Terapi Farmakologi, Potensi Kurkumin dan Analognya, serta Pengembangan Sistem Nanopartikel. Jurnal Pharmascience, 1(5), 25-31. Retrieved from http://10.0.4.153/193758671664 6648\%5Cnhttp://search.ebscoho st.com/login.aspx?direct=true \& $\mathrm{db}=\mathrm{a} 9 \mathrm{~h} \& \mathrm{AN}=117270266 \&$ site $=$ ehost-live

Chintyawati, C. (2014). Hubungan Antara Nyeri Reumatoid Artritis Dengan Kemandirian Dalam Aktivitas Kehidupan SehariHari Pada Lansia Di Posbindu Karang Mekar Wilayah Kerja Puskesmas Pisangan Tangerang Selatan Tingkat.

Hasanah, Umi, N. (2015). Program studi s-1 keperawatan stikes kusuma husada surakarta 2015. 
Nadliroh, U. (2014). Gambaran Penyakit Rematik Pada Lansia Di Panti Wreda Dharma Bakti Surakarta.

dan Determinan Penyakit Rematik di Indonesia. Artikel Penelitian.

Seran, R., Bidjuni, H., \& Onibala, F. (2016). Hubungan Antara Nyeri Gout Arthritis Dengan Kemandirian Lansia Di Puskesmas Towuntu Timur Kecamatan Pasan Kabupaten Minahasa Tenggara. E-Jurnal Keperawatan (E-Kp), 4(1), 1-7.

Tamsury, (2017)

www.definisi.nyeri.ac.id.com

Smeltzer \& bare, 2002 http//www.scrips.acid (diakses26 maret 2013)

Setiawan, R., \& Tjutju, R. (2016). Faktor-Faktor Yang Berhubungan Dengan Kejadian Rematik Pada Lansia Di
Puskesmas Cicalengka

Kabupaten Bandung. Jurnal Keperawatan 'Aisyiyah, 3. 

